\title{
BELAS E FERAS: sua permanência na tradição
}

\author{
Doralice Fernandes Xavier Alcoforado*
}

\begin{abstract}
RESUMO: Os contos do tema o noivo-animal que pertencem ao ciclo de "A Bela e a Fera", coletados recentemente na Bahia, atestam a presença ainda viva no imaginário local de uma tradição oral antiga que vem se recriando a partir, sobretudo, de "matrizes impressas" 1 desse conto-tipo. Uma dessas matrizes é o conto de fada francês "A Bela e a Fera", de Madame Leprince de Beaumont, publicado em 1756, que vem, nos dois últimos séculos, sendo adaptado e difundido em diferentes sistemas de signos, como o cinema, o desenho animado, a televisão, os musicais, a literatura infanto-juvenil, entre outros. Graças a esse processo de refuncionalização, a invariante sobrevive em diferentes contextos culturais.
\end{abstract}

PALAVRAS-CHAVE: conto popular; a Bela e a Fera; "matrizes impressas"; literatura infanto-juvenil.

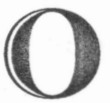
conto "A Bela e a Fera", que pertence ao tema o noivo-animal, na classificação de Aarne e Thompson, ${ }^{2}$ vem sendo documentado no imaginário brasileiro desde as primeiras pesquisas, realizadas no século passado. Levantamento efetuado em publicações e em arquivos de pesquisas sobre o conto popular, algumas em andamento, registrou 99 versões re-

* Universidade Federal da Bahia.

1 Expressão usada por Jerusa Pires Ferreira em titulo de artigo.

2 Estes autores em The Types of the Folktale incluem "A Bela e a Fera" no subtipo o noivo-animal - T 425 a 449. 
ALCOFORADO, Doralice Fermandes Xavier. Belas e feras: sua permanência na tradição.

colhidas em diferentes momentos e lugares, das quais 41 são versões baianas, coletadas nos últimos 13 anos pelo Programa de Estudo e Pesquisa da Literatura Popular, da Universidade Federal da Bahia. Nas versões brasileiras, o noivo metamorfoseado pode vir na aparência de fera, lagartão, teiú, veado, porco, leão, dragão, sapo, boi, camaleão, burro, urubu, cobra, lagartixa, papagaio, pombo, peixe ou mesmo beija-flor. Em pequeno número, o ser metamorfoseado é a noiva que se apresenta sob a forma de jia, serpente, sapa, rã, lebre, abelha ou macaca.

O conjunto de textos do ciclo de "A Bela e a Fera", coletados recentemente na Bahia, antes de tudo comprova a presença ainda viva na memória dos baianos de uma tradição trazida pelos colonizadores e disseminada por todo o Estado, em particular na zona rural onde a integração comunitária e familiar preserva hábitos propiciadores da manutenção dessa prática. Esse conjunto, constituído predominantemente de contos maravilhosos, caracteriza-se tanto pela variedade de tratamento do tema o noivoanimal, como também da sua estrutura narrativa, variedade que norteou a tipologia dessa amostra em cinco subtipos. Embora apresentando uma construção narrativa diferenciada, os contos dos cinco subtipos guardam entre si semelhanças estruturais em torno de um núcleo temático comum - o amor sincero e verdadeiro da jovem, o agente responsável pelo retorno do noivo à sua plenitude humana -, vinculando as histórias ao referido ciclo. Por outro lado, os textos desses subtipos denunciam a procedência de "matrizes impressas", algumas identificadas, o que, por sua vez, deixa à mostra o permanente, recíproco e revitalizante processo de ir e vir do texto cultural, do oral para o escrito, ligando-se a estruturas de maior complexidade, um grande texto, "unificação de diversos sistemas” (Lotman, 1979: 35).

O conto de fada "A Bela e a Fera" de Madame Leprince de Beaumont, publicado em 1756, em versão reduzida do conto de igual nome de Madame Villeneuve, tradicionalizou-se e tornou- 
se a "matriz impressa" mais divulgada e bastante difundida através de diferentes sistemas de signos no decorrer dos dois últimos séculos.

No cinema, o texto de Madame Leprince de Beaumont foi recriado, em 1946, por Jean Cocteau, em “A Bela e a Fera”, primeiro filme sobre o conhecido conto. A adaptação de Cocteau procura ser fiel ao texto matriz em que se inspirou, sabendo tirar proveito dos objetos mágicos na exploração do maravilhoso. Muitas outras adaptações do conto para o cinema e a televisão ${ }^{3}$ se seguiram à realização francesa.

O desenho animado de longa metragem "A Bela e o Monstro”, realizado pelos estúdios Walt Disney, em 1992, é mais uma dessas adaptações do conto. Embora apoiado nos elementos narrativos básicos do conto dessa Autora, o desenho de Disney, ao estruturar-se como opereta, retoma o tema sob a ótica de outras leituras: a de Cocteau, no filme, e a de Mackinley, na narrativa Belle, introduzindo elementos narrativos inovadores que certamente poderão vir a ter repercussão futura na recriação do conto, uma vez que o desenho tem como receptor milhões de crianças do Planeta.

A versão de Madame Beaumont, que se tornou matriz-referência para as recriações posteriores desse conto, por sua vez, certamente procede de uma versão tradicionalizada do conto mítico "Eros e Psiquê" de Apuleio, autor latino do século II, versão escrita mais antiga até então registrada. Acrescentando elementos atualizadores, o texto das autoras francesas introduziu o motivo da rosa e o nome Bela para a heroina, o que explicita se uma versão tradicionalizada resulta ou não da mediação escrita. Paralelamente a essa tradição européia, há uma outra, com certeza mais antiga, que ao invés da rosa, a filha caçula pede ao pai "algo peculiar, um pássaro que pule e cante", "um arbusto com folhas mágicas ou algo dificil de encontrar” (Swahn, 1989: 11), motivo 
ALCOFORADO, Doralice Fermandes Xavier. Belas e feras: sua permanência na tradição.

presente em versões portuguesas e em uma versão brasileira, mas não registrado nas versões baianas.

Os contos de fada de origem francesa tiveram repercussão no Brasil. A França exerceu a hegemonia cultural por longo período, o que determinou que os produtos culturais franceses, mormente a literatura e o teatro, fossem saboreados na lingua original, vez que a classe de prestígio dominava o idioma francês e posteriormente segmentos da classe mëdia. Essa moda reforçou a veiculação de uma matéria que já era fartamente utilizada para o entretenimento nos serões familiares, quando os senhores, empregados e subalternos buscavam, nessas narrativas, forma de matar o tempo, sobretudo, na zona rural, nas reuniões noturnas de trabalho.

Com a utilização da matéria folclórica em livros para crianças, à semelhança da Europa, tem início, na década de 70 do século passado, no Brasil, a literatura infanto-juvenil, constituída de textos não diretamente recolhidos das fontes orais brasileiras, mas de textos estrangeiros que geralmente penetravam via Portugal. As transformações operadas na escola, passando o sistema escolar nacional por reformas de real alcance, repercutiram também na produção literária para crianças e jovens. Cresce a consciência da necessidade de uma literatura infanto-juvenil firmada em elementos da tradição cultural brasileira que incorporou traços das diferentes etnias que aqui se confrontaram e mesclaram, delineando, com o tempo, uma nova realidade cultural. Os livros destinados a crianças, que também veiculavam essa tradição, tornaram-se bastante populares, sendo bem provável que tenham sido a principal fonte impressa da literatura oral brasileira.

Uma vez que a recolha dessas narrativas entre nós, até as primeiras décadas do atual século, foi numericamente insuficiente - publicações esparsas em jornais locais -, pois a primeira edi- 
ção dos Contos Populares do Brasil de Sílvio Romero é de 1885, os livros destinados às crianças continuaram apresentando textos traduzidos e adaptados de antologias portuguesas e de outros paises. O levantamento feito em bibliotecas e seções especializadas em livro infanto-juvenil dá conta de ampla relação de publicações desse gênero. Editoras se tornaram famosas e nacionalmente conhecidas pelas publicações direcionadas a essa faixa etária, que veiculavam textos da mitologia grega e de contos populares de vários países entre os quais aqueles que se referem ao tema do noivo-animal.

Bastante popular tornou-se a editora Quaresma que, a partir de 1879, desempenhou importante papel como pioneira em lançamentos de livros para crianças, inaugurando a coleção Biblioteca Infantil Quaresma, em 1894, com os Contos da Carochinha de Figueredo Pimentel, que vai alimentar a infância brasileira com as histórias de Perrault, Grimm e Andersen. Mais tarde, a exemplo da Quaresma, outras editoras entram no mercado: a Melhoramentos, a Companhia Editora Nacional, a Editora do Brasil, a Vecchi e a Minerva estāo também entre as mais tradicionais. A Editora Vecchi lançou a coleção Os Mais Belos Contos de Fada, em volumes bem encadernados e ilustrados, encontrando-se entre os contos de vários países versões de "A Bela e a Fera". Por exemplo, no volume de contos iugoslavos, encontra-se uma versão de “O Noivo Serpente” (1951: 79-81) na qual uma mãe estéril pede um filho nem que seja um animal, motivo que caracteriza um dos subtipos encontrados na Bahia. No volume dedicado aos contos russos, está presente "A Pluma de Fenist, o Falcão Radiante”, a que outro subtipo baiano identifica-se, conto que pertence à coleção de Afanassiev (1946: 44-8) de cuja descrição dos textos Propp retirou os fundamentos para a Morfologia do conto maravilhoso, título indispensável para qualquer estudo sobre conto popular. Também é da Vecchi Contos de Fadas do Mundo das Maravilhas, Contos de Fadas da Floresta Encantada e Con- 
ALCOFORADO, Doralice Fernandes Xavier. Belas e feras: sua permanência na tradição.

tos Juvenis de Fadas. A coleção As Obras-Primas Juvenis também divulga contos de outros tipos, como os de "As Mil e Uma Noites".

Nessas coleções, foram publicados não apenas contos da tradição oral, como aqueles recriados e mesmo os apenas criados por diferentes autores, entre outros, Irmãos Grimm, Andersen, Perrault, Condessa de Murat, Madame Beaumont, Madame d'Aulnoy, como Os Mais Belos Contos Juvenis em que se encontra “A Bela e o Monstro” em tradução livre, cuja protagonista recebe o nome de Garota Formosa (1946: 66-75). Outras editoras também entraram no filão tipográfico dos contos de fada. Em Ali-Babá e os Quarenta Ladrões, das Edições Lep, está presente a versão “O Príncipe Encantado” (s.d.: 81-8), cujo noivo-animal é um papagaio, como em versões baianas. A Melhoramentos, em Contos de Fadas (1965), traz "O Príncipe Serpente" de Basile e muitos textos de Madame D'Aulnoy, além de contos de outras nacionalidades. A Minerva lançou As Mais Lindas Histórias de Fadas, de Francisco Acquarone, e a Editora Nacional, os Contos Maravilhosos do Brasil, de Teobaldo Miranda Santos.

Não só os livros infanto-juvenis veicularam os contos populares; programas de rádio, colunas de jornal, cordel e, mais recentemente, programas de televisão também os veicularam. Na Bahia, em 1943, o Professor Adroaldo Ribeiro Costa deu início a "A hora da criança", programa de rádio que se manteve no ar por cerca de 30 anos; também no Jornal $A$ Tarde, foi responsável pela coluna "Infantil”, aos sábados, durante 20 anos, na qual publicava narrativas populares recriadas e apresentadas em capítulos, inspiradas no folclore. Uma dessas histórias, "Helena, Helena, Helena”, ouvida de uma velhinha de Salvador, em adaptação livre de Aramis Ribeiro Costa, ẻ uma recriação de “A Bela e a Fera”, posteriormente publicada pela Ática, sob o mesmo título. A partir de 1960, em programas na televisão, as atividades do Prof. Adroaldo voltavam-se direta ou indiretamente para a divul- 
gação da literatura infanto-juvenil da qual fazia parte a matéria folclórica.

Na televisão, Sítio do Picapau Amarelo seguramente foi o programa infantil de maior duração, maior aceitação e penetração. Apesar de destinado a crianças, também despertava interesse do público adulto. Por meio desse programa, a "obra de Monteiro Lobato, com o seu universo de personagens fascinantes, chegou à televisão brasileira" (Vale, 1994: 141). Iniciado em 1952 pela TV Tupi, onde esteve no ar até 1963, o programa, além de divulgar a obra infantil lobatiana, através de encenações de episódios dela retirados, também estimulava a leitura dos textos. De 1967 a 1969, foi transmitido diariamente pela TV Bandeirantes. De 1976 a 1985, Sítio do Picapau Amarelo retorna ao ar, transmitido pela Rede Globo de televisão, com nova estrutura, um grande elenco, filmado em um sítio real, atingindo um público de milhões de brasileiros. Mantendo o humor e o tom crítico da obra, os episódios, construídos com esse espírito e explorando determinados temas, encantavam e divertiam todos aqueles que a ele assistiram. O Sítio do Picapau Amarelo levou ao ar algumas adaptações de contos populares. Uma das versões de "A Bela e a Fera", da recolha da Bahia e estudada neste trabalho, foi aprendida nesse programa, segundo informação da sua transmissora: "Eu sei assim. Foi o que eu assisti no Sítio do Picapau, foi isso.”:

Um mercador, em viagem, procura atender ao pedido da filha caçula que, contrariamente às suas duas irmãs, encomenda-lhe apenas uma rosa. Ao regressar, já sem dinheiro, ao ver uma linda rosa, pula um muro para colhê-la. Guando vai deixando o local, um horrendo monstro aparece e pergunta-lhe porque pegou a rosa sem the pedir. Após ouvir a explicação, o monstro consente que a leve, mas em troca da sua vida, exige a entrega da filha no prazo de três dias. $\mathrm{O}$ pai, ao regressar, entrega a rosa à filha, mas omite-lhe o 
ALCOFORADO, Doralice Fernandes Xavier. Belas e feras: sua permanência na tradiçāo.

acontecido que só vem a ser descoberto depois de insistentes perguntas sobre a causa da sua tristeza. A filha decide ir ter com o monstro, para o que tem de fugir. O monstro se apaixona por ela e, para não perdê-la, a aprisiona no castelo. Posteriormente arrepende-se e a liberta. Retornando à casa paterna, a moça não suporta a ausência do monstro e resolve voltar, porque também o amava. Certo dia, ao ter a cabeça do monstro no colo e, começando a acariciá-lo, dálhe um beijo. Ele se transforma, no mesmo instante, em um principe. (EBR-593.2) ${ }^{3}$

Essa versão integra um dos subtipos do ciclo de "Bela e a Fera" recriado a partir do texto francês. Encontram-se na pesquisa da Bahia duas versões desse subtipo, cujo noivo-animal apresenta-se na forma de monstro. Talvez pela impossibilidade de enquadrá-lo em uma taxionomia da espécie animal, a figura do monstro, traduzida em palavras, é descrita como um ser morfologicamente anômalo e disforme: "homem do oi só na testa" ou "bicho dum olho na testa desse tamanho!" (EBR-593.2). O ato da linguagem tem a propriedade de transformar virtualidades em algo concreto, de passar "a sensação do objeto como visão" (Chklovski, 1971: 45) e, com isso, fazer prolongar a duração da percepção, conseqüentemente perdurar o efeito de estranhamento. Essa iconicidade, que dá forma a estruturas miticas, torna o símbólico mais inteligivel, à semelhança do próprio Polifemo, imagem introduzida na tradição oral certamente através do texto da Odisséia. Semelhante representação encontra-se em outra figura que povoa o espaço mítico amazônico, o Mapinguari (Pimentel, 1976: 37), que tem um único olho e também é vencido graças às

3 EBR corresponde à sigla formada pelas iniciais do projeto Em Busca do Romanceiro; os três algarismos correspondem ao número com que o contador da história foi registrado no arquivo do Programa, e o último, ao número de ordem do texto fornecido por ele. 
artimanhas do herói que, como Ulisses, assim consegue escapar das suas garras. ${ }^{4}$

O motivo da rosa pedida pela filha caçula encontra-se presente nessa versão - "a mais nova pediu uma rosa vermelha muito bela." (EBR-533.5) -, o que atesta a vinculação dessa versão baiana à fonte impressa francesa que, com certeza, também foi veiculada por meio da literatura infanto-juvenil. A rosa representa o objeto do desejo da moça e, ao mesmo tempo, é a metáfora do príncipe:

Ele entrou e roubou a rosa, a rosa mais bela que tinha, que era a vida do monstro. Só que ninguém mexia nesse jardim porque a vida dele tava ali. (EBR-533.5)

Percebem-se, sem muito esforço, na transmissāo do texto, soluções performáticas pertinentes ao modo de recepção de um texto via televisão. A forte iconicidade das imagens reforça e reitera sobretudo a tensão dramática de algumas cenas, como a do súbito aparecimento do monstro questionando o pai pela retirada da rosa e a cena final de intenso romantismo em que a heroína sela com um beijo, na monstruosa personagem, a sua jura de amor, qual sopro de vida que o desmetamorfoseia, de imediato, em garboso principe. O amor sincero da moça é capaz não apenas de restabelecer a saúde do monstro, mas ainda remover "o feitiço que a bruxa tinha feito pra beleza dele ficar naquela rosa” (EBR-533.5), restituindo-lhe a plenitude humana, o que significa que à mulher, cabe essa missão.

4 Na tradição brasileira aparecem outros contos com igual motivo. Braulio do Nascimento, em "Um Catálogo do Conto Brasileiro" (texto mimeografado), faz referência a duas versôes recolhidas na década de 40 por Aluisio Almeida em São Paulo. Em uma delas, o monstro é um Caipora. Na Bahia o Programa de Estudo e Pesquisa da Literatura Popular também recolheu uma versão com a figura do Caipora, com um único olho na testa, embora o motivo do noivo-animal não se encontre presente. 
A retomada de um texto è o testemunho cabal da sua permanência na tradição; cada alteração que se lhe imprima mostra a capacidade de articulação que esses textos oferecem como "formas diferentes de dizer o mesmo" (Nascimento, 1994: 455). O desenho de Disney, por exemplo, inova no que diz respeito à seleção e apresentação das personagens. O tom chistoso com que se mostra o antagonista deixa implícito uma crítica ao modelo de mulher da ótica machista, chamando a atenção do espectador para a refuncionalização dos papêis sociais dos sexos e, conseqüentemente, para a mudança de paradigmas dessa relação, adequando-os aos tempos atuais.

Através dessa variação, a invariante afirma a sua permanência. E assim, desse jogo de leituras cruzadas de "A Bela e a Fera” da versão de Disney, resulta um texto leve, divertido e verdadeiro, do ponto de vista da arte, capaz de despertar risos, ódios, mas tambêm de comover até às lágrimas, a exemplo do que foi registrado: a platéia chora pela morte do Monstro.

Assim como o texto de Disney, as versões baianas de "A Bela e a Fera", introduzindo na invariante elementos inovadores e dados atualizadores da realidade regional, não apenas mantêm viva a tradição desse conto-tipo, como também permitem a continuidade e a inovação dos textos que lhe antecederam. E nisso está a importância de cada nova adaptação. Numa cadeia sem fim, a variante conduzirá a novos textos. Em realidade, esse novo texto é o mesmo e é o outro, possibilitando, dessa forma, a permanência da invariante.

\footnotetext{
ABSTRACT: Tales on the animal-groom theme, recently collected in Bahia, attest the still vivid presence in local imagery of an ancient oral tradition that has been re-creating itself, particularly from "printed matrixes" of such type-tales. One of these matrixes is the "Beauty and the Beast" fairy-tale by Madame Leprince d Beaumont, published in 1756. Over the last two centuries it has been adapted
} 
and disseminated under different sign systems, such as the cinema, animated films, television, musicals, juvenile literature, among others. Thanks to this re-operative process, invariance survives within different cultural contexts.

KEYWORDS: Fairy-tale; Beauty and the Beast; "printed matrixes"; juvenile literature.

\section{Bibliografia}

AARNE, Antti \& THOMPSON, Stith (1981) The types of the folktale. Helsinki: Academia Scientiarum Fennica.

ACQUARONE, F. (1962) (Org.) As mais lindas histórias de fadas. Rio de Janeiro: Minerva. A Bela e a Fera.

AFANASSIEV (1978) Contes russes. Paris: Maisonneuve et Larose.

APULEIO, Lúcio (s.d.) O Asno de Ouro. Trad. de Ruth Guimarães. Rio de Janeiro: Edições de Ouro.

BEAUMONT, Leprince de \& d' AULNOY (1979) La Belle et la Bête et autres contes. Paris: Hachette.

BENJAMIN, Roberto (1994) (Org.) Contos populares brasileiros: Pernambuco. Recife: Fundação Joaquim Nabuco / Ed. Masangana.

CAMPOS, João da Silva (1939) Contos e fábulas populares da Bahia. In: MAGALHĀES, Basilio de. O folclore no Brasil. Rio de Janeiro: Imprensa Nacional.

CASCUDO, Luís da Câmara (1985) Contos tradicionais do Brasil: folclore. Rio de Janeiro: Ediouro.

COELHO, Nelly Novaes (1982) A literatura infantil. 2. ed., São Paulo: Quíron /Global.

CONTOS DE FADAS (1965) Trad. de Aluysio Ferraz Pereira. 2. ed. São Paulo: Melhoramentos. O principe serpente.

FERREIRA, Jerusa Pires (1994) Matrices imprimées de l'oralité. In: COLLOQUE APPROCHES CROISEES DES LITTERATURES POPULAIRE ET ORALE, 1994, Limoges, Actes... Frontières du littéraire. Limoges: Université de Limoges. p. 51-7. 
ALCOFORADO, Doralice Fernandes Xavier. Belas e feras: sua permanência na tradição.

HOLBEK, Bengt (1990) Le langage des contes merveilleux. Cahiers de littérature orale. Paris, n. 28, p. 127-62.

KAPPLER, Claude (1994) Monstros, demônios e encantamentos no fín da Idade Média. Trad. de Ivone Castilho Benedetti. São Paulo: Martins Fontes.

LAJOLO, Marisa \& ZILBERMAN, Regina (1984) Literatura infantil brasileira: história \& histōrias. São Paulo: Ática.

LIMA, Francisco Assis de Sousa (1985) Conto popular e comunidade narrativa. Rio de Janeiro: FUNARTE / Instituto Nacional do Folclore.

LOURCELLES, Jacques (1991) Dictionnaire du Cinéma. Paris: Robert Laffont.

MCKINLEY, Robin (1993) Belle. Trad. de Sophie Dalle. Paris: Presses Pocket.

NASCIMENTO, Braulio. A literatura oral: limites da variação. In: IX ENCONTRO NACIONAL DA ANPOLL, 12-16 junho, 1994, Caxambu-MG. Anais... João Pessoa, ANPOLL, 1995. v. 1 - Letras.

OS MAIS BELOS CONTOS DE FADAS FRANCESES (1959) 4. ed. Rio de Janeiro: Vecchi.

OS MAIS BELOS CONTOS DE FADA IUGOSLAVOS (1951) 3. ed. Rio de Janeiro: Vecchi.

OS MAIS BELOS CONTOS DE FADAS RUSSOS (1946) 2. ed. Rio de Janeiro: Vecchi.

PIMENTEL, Altimar (1987) Estórias de Cabedelo I: narrativas de encantamento. Brasília: Thesaurus.

PIMENTEL, Figueredo (1952) Contos da carochinha. 22. ed. Rio de Janeiro: Quaresma.

PROPP, Vladimir I (1984) Morfologia do conto maravilhoso. Rio de Janeiro: Forense-Universitária.

ROBERT, Raymonde (1982) Le Conte de fée littéraire en France: de la fin du XVIIè. à la fin du XVIIIè. siècle. Nancy: Presses Universitaires de Nancy.

ROMERO, Sílvio (1985) Folclore brasileiro: contos populares do Brasil. Belo Horizonte: Itatiaia; São Paulo: Ed. da Universidade de São Paulo.

SANTOS, Theobaldo Miranda (1958) Contos maravilhosos do Brasil: os mais belos contos tradicionais de todas as regiões do Brasil. 3. ed. São Paulo: Companhia Editora Nacional. (O príncipe encantado). 
Rev. ANPOLL, n. 9, p. 41-53, jul./dez. 2000

SWAHN, Jan-Öjvind. Beauty and the Beast in oral tradition. Merveilles \& Contes: Beauty and the Beast. Boulder: University of Colorado, v. 3, n. 1, p. 15-27, may 1989.

THOMPSON, Stith (1972) El cuento folklorico. Caracas: Universidad Central de Venezuela. (Ediciones de la Biblioteca).

VALE, Fernando Marques do (1994) A obra de Monteiro Lobato: inovações e repercussões. Lisboa: Portugalmundo.

ZUMTHOR, Paul (1993) A letra e a voz: a "literatura" medieval. São Paulo: Companhia das Letras. 